\title{
Antroquinonol Capsule
}

National Cancer Institute

\section{Source}

National Cancer Institute. Antroquinonol Capsule. NCI Thesaurus. Code C119701.

An orally available capsule containing antroquinonol, a farnesylated quinone derivative isolated from the mycelium of Antrodia camphorata, with potential antineoplastic activity. Upon oral administration, antroquinonol binds to and inhibits protein prenylation mediated by the enzymes farnesyltransferase (FT ase) and geranylgeranyltransferase 1 (GGT ase-1). This prevents both post-translational prenylation and signaling activity of a number of Ras superfamily proteins, such as Ras and Rho. This results in the inhibition of downstream signaling, such as the PI3K/mT OR signaling pathway, and induces apoptosis in susceptible tumor cells. Ras superfamily proteins are overexpressed in numerous cancer cell types, and play a key role in tumor cell proliferation and survival. 